\title{
IMPROVING SUSTAINABLE ENHANCEMENT OF CULTURAL HERITAGE: SMART PLACEMAKING FOR EXPERIENTIAL PATHS IN POMPEII
}

\author{
M. SEPE \\ IRISS-National Research Council, DiARC - University of Naples Federico II, Italy.
}

\section{ABSTRACT}

The senses are part of our everyday life and the sensory experience we had of a place makes us remember it more or less distinctly and with more or less pleasure. Urban studies agree on the fact that today the main goal of urban space planning is to alter the experience of that space for those who inhabit it. Urban environments are increasingly often designed to be distinctive; they strive to create memorable sensory experiences for the people who use them. The experience of a place can be further improved and virtualized by using smart technologies to be applied to a given area in all its complexity, making the most of both its tangible and intangible resources. The present study was undertaken to contextualize the issue of place experiential paths. It was carried out in the framework of the research project, 'Historic urban landscape as a resource for local development: an innovative approach for smart strategies for the creation of value', formulated according to PRIN - Project of Relevant Italian National Interest - guidelines. Starting from the evolving definition of 'experiential path', this study seeks to illustrate the projects currently being developed for Pompeii and the PRIN proposal for a smart experiential path in the Pompeii area. This area is characterized by archaeological resources of great interest, but scarce attractiveness of the modern town next to the ruins. The identification of well-known and less well-known cultural and identity resources of these places is the basis for the construction of experiential paths capable, thanks to smart technologies, to contribute to its sustainable enhancement.

Keywords: creativity, experiential paths, place identity, smart innovation, sustainable development.

\section{INTRODUCTION}

One of the most recently introduced means to develop an area is the creation of integrated systems for the management of cultural resources to be enjoyed through experiential paths. These paths are designed to identify existing heritage and, at the same time to support and/or stimulate the development of creative industries $[1,2]$. The experiential knowledge of a place can be further improved and virtualized by using smart technologies to be applied to the land-managing system in all its complexity. The emergence of the internet as a medium of communication, besides dematerializing the landscape and cancelling physical distance, has also opened up spaces and their users to new meanings and uses. The web contributes to the construction of the living spaces of its inhabitants; now that it, too, is configured as an urban space, it creates new landscapes and aggregations of functions. In addition to relating to natural and urban contexts, buildings extend their connections, linking up with the structures created by cyberspace through electronic processors, which enable their interactions.

The strategic dimensions upon which the smart cities concept is based are mobility, environment, tourism, culture, economy of knowledge and quality of life. Faster movement, supported by sustainable transport and new solutions for mobility, tourism and culture - based on the connection of green networks with systems of cultural values, partially achieved through the creation of thematic paths and the construction of a virtual image capable of improving competitiveness - are all elements contributing to the smart transformation and promotion of the landscape [3]. To contextualize the theme of experiential landscape paths, the present study, carried out as part of a research project entitled, 'The historic urban landscape as a resource for local development: an innovative approach for smart strategies to value creation', a PRIN - Project of Relevant Italian National Interest - aims 
to illustrate their definitional aspects and evolution, and look at ways to sustainably organize the landscape to accommodate these paths.

Studies on experiential paths are rooted in the disciplines of psychology and economy, and, more recently, in disciplines that study the landscape. A brief introduction to the placemaking concept will help to bring into better focus the perspective adopted in the present essay. The case study of Pompeii, which I am currently working on, concludes this paper. As Section 4 will explain, the aim of the present essay is to identify cultural and identity resources capable of expanding and differentiating archaeological heritage resources and create a smart and sustainable experience of the landscape [4]. Indeed, the virtual experience of Pompeii connected with the physical one through the use of Div@ter platform, which can be uploaded with smart tablet and phone, is capable to offer to the visitors a more deep and attractive idea of the place. The results are consistent with the objectives of the 'Major Project Pompeii - MPP' and 'Restoring life in Pompeii: a sustainable development project for the Vesuvius area' project, illustrated in the following section.

\section{THE POMPEII PROJECTS IN DEVELOPMENT}

The outstanding archaeological area of Pompeii is the focus of many conservational projects. Two of these are specifically of interest for the study presented in this paper. The main, the 'Major Project Pompeii - MPP' which has been financed by Interregional Operative Programme 'Cultural and natural attractors and tourism' (FESR2007-20013, POIn) and involves a huge private-public partnership, has as an objective, which will not only be to safeguard both the history and beauty of the place but also to preserve it through ecological, hydrogeological and structural interventions. The other important project - 'Restoring life in Pompeii: a sustainable development project for the Vesuvius area' has been carried out by the Study Centre of the Industrial Union Association [5]. The project is devoted to creating a cultural touristic district in the external parts of the archaeological area, proposing new and attractive services.

In particular, the research has identified two new trends within the tourist demand. First, the demand of participation in a more active way of the cultural activities proposed by the place in question. Secondly, the necessity to create a profound experience, full of both cultural and perceptive meaning.

The cultural district of Pompeii is aimed at repositioning the Pompeii ruins offer to attract both tourists in search of a deeper and involving cultural experience and those who do not stop there because of the lack of a suitable offer.

That project is aimed at transforming the touristic identity of Pompeii, which will not be only the main archaeological site of the ancient Rome period but the more advanced cultural centre at the international level to know life, use and customs of that period.

To achieve this, the project proposes to realize an integrated system of services, which are complementary to the ruins and represent a reason for the tourist to continuing the staying in Pompeii more than the period of the visit at the ruins.

The strategies' priorities to realize the project include (Figs 1 and 2):

- strengthening the experience of the visit to the ruins through services devoted to the learning supported by technological and interactive tools which allow the visitor to know the life of ancient Pompeii;

- widening the touristic experience allowing the visitor to taste some particular moments of the ancient Pompeii Life;

- realizing a widen hotel accommodation offer close to the Pompeii ruins with quality standard and attract people to visit not only Pompeii but also the other close activities. 

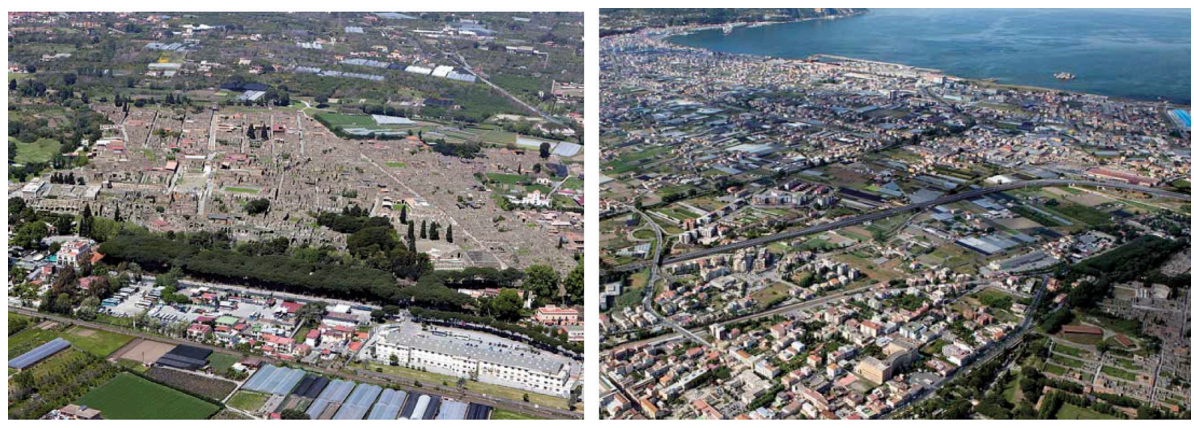

Figure 1: (a and b) Pompeii archaeological area and the sea (Source: [5]).

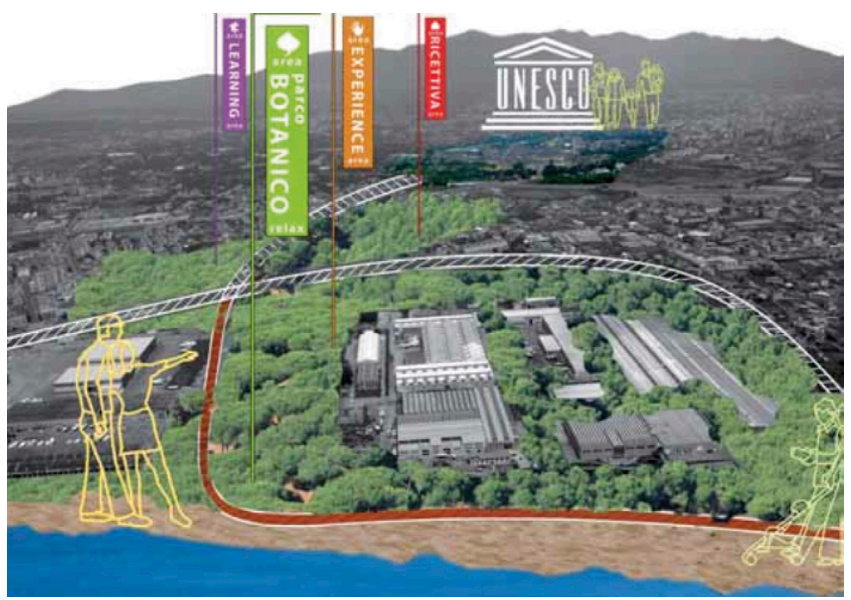

Figure 2: Details of the Pompeii project (Source: [5]).

The guidelines to achieve these objectives include:

- reconnecting ancient Pompeii, which in the ancient period faced directly on the bay of Naples, with the sea through suitable project interventions aimed at creating a connection between the sea and the port;

- joining some stretch of the area that make this territory fragmented realizing a green area, which work as a connective tissue suitable to welcome new touristic structures;

- respecting the outstanding value of the landscape through low environmental impact architectonic solutions;

- enhancing the transport system to favour the connections from and to the main cultural direction close to Pompeii;

- realizing transport connections within the cultural district in sustainable way.

All these measures should guarantee a suitable enhancement of Pompeii and its surroundings. 


\section{EXPERIENCING PLACES}

The projects being developed for the Pompeii area, whose scope goes beyond the enhancement of the archaeological site, aim to create an intense experience of place. The study presented in this paper, in the framework of the PRIN research project, is consistent with this approach. To illustrate the concept of 'experience', I will go over both theoretical and practical aspects. A brief introduction to the concept of 'placemaking' will help to bring into better focus the specific experiential viewpoint adopted in the present paper.

\subsection{Placemaking}

Placemaking can be defined - paraphrasing the definition of urban design reported by Cabe - as 'the art of making places for people. It includes the way places work and matters such as community safety, as well as how they look. It concerns the connections between people and places, movement and urban form, nature and the built fabric'.

The importance of the relationship between places - in its wide meaning - and people was first mooted in the early 1960s, when new ways of interpreting the urban environment arose in the USA and England. The key figures in these studies are Kevin Lynch and Gordon Cullen, whose theories can be considered - for their particular attention to the perception and design of place and its identity - the origin of placemaking.

Lynch and Cullen's ways to interpret the city have been implemented over the years. Nowadays, changes in the contemporary city are extremely rapid. The urban image referred to by Gordon Cullen is no longer a typical example of the urban landscape. The rapid consumption of culture which is affecting many historic places devoted to chiefly economic advantage is leading to the loss of place identity that increasingly becomes hybrid and compromised [6].

One of the consequences is the creation of places which are not authentic and where locals feel less and less inhabitants. The typical visitor is commonly attracted by places where it is possible exploiting the greatest quantity of attractions with the least waste of energy and time, contributing to the acceleration of aggressive territorial marketing. Preserving the place identity, meant as a fundamental component of the culture heritage, is now increasingly at risk due to a contemporary trend at homologation of places, which makes the cities and towns similar to each other. With the aim to acknowledge the new urban topics, 'the art of making places for people' has updated its theory and has added representational tools to become suitable to illustrate more complex urban scenes and help to experience them more profoundly. Indeed, computer science and new technologies have in recent decades become increasingly useful supports and more for improvement of studies and applications in the field of area investigations.

\subsection{Defining experience}

Studies on experiential paths are rooted in the disciplines of psychology and those of the economy, from which the current disciplines studying the landscape evolved.

David Kolb [7], one of the greatest experts of Experiential Learning in the field of psychology, defines learning as 'continuing education of the individual'. Learning benefits from various connections were created between education, work, and personal development. The individual thus acquires a 'system of skills through experiential methodologies, which lead to the development of educational goals adhering to the real world of work.' Experiential learning is a modality of learning, which is based on experience, understood in its cognitive and sensory senses. By experimenting with situations, tasks and roles, the subjects, as active protagonists, it organizes their resources and 
expertise to pursue their goals. In the field of economic studies, 'experiential' acquires a more extensive meaning, more akin to the concept of 'landscape'. Three periods can be distinguished, from the 1980s onwards, in which distinctive patterns of consumer behaviour in terms of experience evolved.

The term 'experiential' was introduced in 1982 'as an approach that focuses on the symbolic, aesthetic and hedonistic nature of consumption, and which is based on the conception of the experience of consumption as an activity aimed at searching for amusements and sensations' [7].

It was later shown that the rational and emotional component can coexist and influence the degree of satisfaction, introducing an experiential vision in the consumer. Recognition of the importance of variables such as the emotions that bring pleasure and the need to actually use a given product, as well as the action of purchasing itself, became important components of product design. As Capitello et al. [8] note, new concepts were introduced, such as 'shopping experience' $[9,10]$, 'Internet shopping experience' [10] and 'customer experience aimed at creating competitive value.'

In the 2000s, new studies on customer experience have proposed a holistic experience bringing together the customer and the company's offer so as to achieve the optimal experience in the gaining of knowledge and in product buying. While this approach can offer a significant competitive advantage to a company, it requires an especially accurate study of the offer in terms of experience. It also requires the company to be able to differentiate its offer to meet different needs; this leads to customization and an increase in time and costs compared with traditional offer designs. Decisive factors in this regard are, besides the quality and reputation of the product being offered, the attractiveness of the place and the functionality of its services, and intangible values 'such as tradition and the hospitality of the population' [8].

Place experience thus becomes an integral part of the product experience. The enhancement of products [11] takes on a meaning that goes beyond the simple sale of material goods. It extends to the supplying of complex experiences (...) enriched by intangible elements capable of stimulating and involving the sensory and experiential component of consumption. Place experience has to do with attracting people to the places where local products are made by including products in a more generalized offer addressed to the entire target area. The overall supply does not consist just of single product; rather, it consists of a system where one or more enterprises, local institutions or entertainment facilities promote a new image of the area. Demand thus turns into demand for experiences, and this, in turn, requires appropriate hosting structures.

\subsubsection{Local networks}

The construction of a local system to support experiential activities requires the definition of appropriate network modalities. A study by Splendiani et al. [12], while it actually deals with the promotion of local products, outlines a logic of interest that can also be extended to other types of cultural 'products'.

As Montella explains [13], 'In the case of local systems for the promotion of local products, the most appropriate organizational models present "variable geometry", according to different thresholds of efficiency and effectiveness that characterize different kinds of internal processes to the network.'

Two methods of network construction can be recognized. One is characterized by a bottom-up logic of organization consisting in the convergence of different actors towards a common idea of task management, to the purpose of carrying out a common project. The second one is mainly top-down; the construction of the system provides a governing body that manages the aggregation of the different actors and planned activities and is expected to last over time [13,14].

The purpose of the resulting supply system makes the user no longer a passive subject of standardized economy, but an active subject involved in the production and consumption processes, as 
well as capable of creating value. The concept of value is also extended to local stakeholders, who contribute to the construction of the network. Value is thus 'created jointly between the parties involved (...) transcending the boundaries between functions and specialized disciplines and taking a holistic view that, at the district level, implies a setting of marketing network, where there are no buyers and sellers, but partners who exchange resources to carry out jointly interdependent activities aimed at the preparation of experiences' [11]. The 'exhibition' of experience has an operative potential in the support of the development of creative forces. This approach originates in the studies of the economist Florida, but has evolved to encompass the impact that the creative approach has on the landscape [15-19].

\subsubsection{Creating sustainable paths}

As a matter of fact, the development of a creative district cannot leave aside from a sustainable development intended in economic, social and environmental sense, which are meant as conditions which are equally important and interdependent for sustainability [20].

Economic sustainability can be defined as the 'the ability to generate income, profits and work inside a system of equal opportunities for all the elements of society, inside a model which enhances and increases the resources of territory, and furthermore does not produce a collapse of the same in quantitative and qualitative terms'. The characteristics of territory, seen as a complex system where the tangible and intangible cultural resources become elements of a chain of added value, assume a key role in the development of the local system. In this way, the district, starting from the elements of territory and their enhancement and promotion, will present the characteristics of economic sustainability in the long term.

Social sustainability is the 'ability to ensure welfare conditions and opportunities of growth equitably distributed in society'. The setting up of a model of development based on the enhancement of culture fosters social regeneration of the area, generating in people a perception of belonging. The cultural production and use perform functions of generation and dissemination of creative thinking. Furthermore, this use provides tools for the growth of individual opportunities by creating a process for the social sustainable development of territory.

With respect to environmental sustainability, the territory should be understood in its various historical and cultural values, and in its tangible and intangible capitals. In fact, territory is characterized by both capitals and its identity cannot leave apart from them. However, even if the consequences of exhausting of material resources on the nature of territory are known, with regard to those immaterial are less evident, although they are as much important, and indeed ensure maintenance of those materials. It is, therefore, necessary to create a close relationship between production systems and central territory, so that companies do interact - inside the values chain - the processes which generate value for territory $[20,21]$.

The aim of the detailed organization of experiential paths is to raise awareness among the inhabitants of a given place, and innovatively promote an area through its products and cultural values.

One of the first examples of experiential paths are 'typical paths', which are aimed at the promotion of local products with an emphasis on the experiential dimension and the resources offered by the area they are an expression of. The purpose of typical paths is to present a product and thereby reap social and symbolic benefits. An interesting example in this regard is the Wine Routes instituted by Italian national law no. 268/1999 - Discipline of Wine Routes [22].

The paths centred on the experience of typical products are an example of negotiation between the various forms of exploitation of the resources of an area. They are also an important opportunity for the development of disadvantaged and marginalized areas, as they can catalyse the interest of institutions, producers and inhabitants in joint projects. The actors involved, motivated by the idea of 
addressing what they have to their offer to a broader context of users, strive to build a network of relationships with manufacturers and other entities participating in the initiative to promote an area. The success of the strategy depends on individual producers' willingness and ability to coordinate. Their synergy can be a real-added value and open up experiential vistas [11]. Ongoing initiatives throughout Italy, including some in Trentino, are a prime example of this approach, demonstrating how these routes are capable of raising interest. Websites on wine trails provide detailed information about the different modes of knowledge of an area and its products, enabling the user to make a decision in relation to the type of experience that is offered to him or her. In the area studied in the following pages, there is a Vesuvius Wine Route (http://www.stradadelvinovesuvio.com/) aimed at the promotion of wine and other typical products in the area of the Park of Vesuvius, together with the area's natural resources and landscapes.

\section{THE CASE OF POMPEII}

\subsection{Smart placemaking}

The experiential component of an itinerary has been studied more recently by architects and planners who have developed theories on the perception of place, in the wake of Kevin Lynch [23]. As reported in a study by Degen and Rose [24], the British 'urban renaissance' agenda - concerning the regeneration of many British cities - has given considerable attention to the quality of urban design, whose assumption is that it arises directly from people's place experience: 'a good design can help to create lively places with a distinctive character, streets and public spaces that are safe, accessible, pleasant to use and at human scale, and places that inspire a positive atmosphere, thanks to the imagination and sensitivity of the designers' [6]. The authors also point out the importance of urban transformations of the built environment as a reflection not only of political, economic and cultural changes, but also of the 'everyday experience that people have of the urban space'. The senses are part of people's everyday life, and the sensory experience made in a place makes us remember it in a more or less pleasant and distinctive way [25].

Urban studies agree on the fact that, increasingly, the goal of project action in the urban space is to alter the experience of that space for its residents. Urban environments are increasingly designed to be distinctive, trying to create memorable sensory experiences for the people who use them. Even people who visit ordinary urban centres can describe a number of emotional experiences concerning those places based on one or the other of the five senses. These experiences can be very different from one place to another. An experience may also vary in relation to factors such as the use of vehicles or the experiencing of a place on foot.

The sensory experience may also be used for the spectacularization of a place and its commercialization, as in the case of 'brandscapes' [26], leading to possible cloning of places that inevitably resemble each other and are incapable of emotionally involving the people who move through them [27].

To complete the experience of a place and its urban environment we need, as Seremetakis claims [28], to resort to acts of memory. Recalling how such a place can be different in the past not only relates to a given environment in its current form but it also connects to what it looked like in the past. When a neighbourhood is perceived as being similar to any other town centre or shopping mall, it is defined as a 'type' rather than a unique urban environment. As Eizenberg argues [29], 'the continual remembrance of other places and previous visits to the same place, both assimilates a person into the experienced place and constantly makes reference to other places elsewhere' [30].

Nowadays, new tools are used to support our knowledge of places. The introduction of new technologies has helped researchers to study local areas more in depth. 
The emergence of internet as a medium of communication in Europe in the last 20 odd years has not only produced the dematerialization of the territory and the cancelling out of physical distance but also opened up spaces and their users to new meanings and uses [31]. In a time of economic crisis, its ability to reduce costs and speed up relation times has increasingly established it as not just a tool but a method for achieving new interpretations of the territory and forms of socialization $[14,32]$.

The use of internet has led to a different approach to citizen participation. Community hubs, network thinking and social networks are only some of the current relational modalities among web communities. High-technology infrastructures are used in a new culture of exchange, creating new possibilities of interaction within the communities. The tension that may result can have outcomes which are difficult to foresee, introducing unexpected features of territorialization and contextualization. Thanks to the innovatory contribution of these infrastructures, territorial usage is being reorganised, creating contexts where social exchange comes to replace the more traditional contexts. Such processes are not easy to identify because the visible evidence does not always correspond to the transformations in progress.

Such cyber communities have the common goal of supporting specialised social groups, which are often geographically distant [33]. The success of these cyber groups is due in the first place to the fact that the networks support 'imaginary communities' [34] without the barriers imposed by the physical urban space. In this perspective, internet is the means that has enabled the development of social networks and led some to speculate about a global society based on networks [35]. One of the uses of new technologies and the network is augmented reality: using physical and virtual tools, it is designed to enrich 'human sensorial perception by means of information, generally manipulated and conveyed electronically, which would not be perceptible using the five senses' [36]. There are in fact many combinations of physical and virtual that can be implemented to fulfil a range of different uses.

In the direction of these combinations, it will spawn the smart cities [3]. Infrastructure we have become accustomed to using in a different manner by the cyber city is at the heart of what today is known as the 'smart city', in which the whole range of technologies are at the service of the city both to improve the quality of life and ensure its sustainability. In this case, the hybridizations vary widely in terms of both significance and application, so that the issues are at times hard to define.

They are put in order the elements of the tangible and intangible assets that can contribute to the attractiveness of the city, creating a vision of experiential paths and parts of the city. This view is favoured by the presence of a quality urban environment and a creative class.

Experiential routes exemplify the smart use of ICT as a tool to support local knowledge through interactive and multimedia devices. An interesting example of this is the 'project path' of Pisa (within the PIUSS, www.pisa2015.org), aimed at promoting tourism with pedestrian paths of cultural value supported by multimedia tools. Along the routes are multimedia kiosks with Wi-Fi access, providing tourist and cultural information through mobile apps. Here, we have a system for the use of cultural heritage whereby the values and symbols of an area are promoted in a sustainable manner [37].

\subsection{Experiencing Pompeii}

\subsubsection{The Prin and Div@ter projects}

This case study has been carried out in the framework of the PRIN - Project of Relevant Italian National Interest titled 'The historic urban landscape as a resource for local development: an innovative approach for smart strategies to value creation' - and the Div@ter - Dynamic and interactive platform for the complex-sensitive management of the qualitative data of a territory - project financed by POR FESR Lazio Region 2007/2013 Axis 1 - Activity 1.1. 
The PRIN project starts from the idea that 'the hard values, the tangible, material and monetary ones are dominating, while the soft values, the intangible, immaterial and non-monetary ones are forgotten. (...) By integrated approaches, it is possible to reach the balance between conservation and transformation, respecting values and existing forms of capital (human, social, cultural, environmental, economic, etc.). (...). Tangible and intangible values lead knowledge/interpretation and select the way to look at the territory, researching (local and numerous) specific codes and the significant available resources. (...) This implies a consciousness of the complex social value of the territory, constituted by primary (intrinsic) values and secondary (instrumental) values. Intrinsic value expresses the spirit of a place, its specific, unique, non-reproducible character, its particular identity, the emotional link exiting between social, man-made and natural capitals. Intrinsic value constructs integration, reduces marginalization, goes over fragmentation, and stimulates vitality. It is a catalyst of material and immaterial energies, able to link different dimensions of value, helping to understand the deep unity.

In that sense, the general aim of the PRIN research is: 'elaborating a methodological process that combines the contribution of different expertise to implement an innovative and smart local development model based on dynamic landscape concept, in continuous evolution and transformation, multidimensional an complex, where different systems of relationships interact, sometimes able to self-regenerate and become catalyst of virtuous processes'.

The identity resources for the Pompeii case study are collected by the use of the Div@ @er dynamic and interactive platform. The Open Source platform, in course of development, allows to import tangible and intangible spatial data from different sources, integrates them with information provided by the users, calculates indicators and represents the information in interactive and immediately understandable maps [38].

Furthermore, Div@ @er is a Geographical Business Intelligence tool devoted to the re-design of the territory, which is conceived as a unique platform with different entry points, both private and public: for local authorities, professionals, and citizens.

It collects the main data using the PlaceMaker method, already experimented in many contexts - including Europe, USA, China, and Japan - and for different objectives, integrating them with structured data and enabling the development of new services based on them. The PlaceMaker method is an urban analysis and planning method. Its aim is to identify elements that are not recognizable in traditional maps and constitute the contemporary identity of places, and to outline suitable actions for the protection and sustainable development of these places. By employing a protocol that is at once rigid and flexible, the PlaceMaker method assembles, elaborates, and reconstructs data from surveys based on physical reconnaissance, sensorial perceptions, graphical elaboration, photographic and video records, and sets these data against those provided by an overview of expectations, an analysis based on traditional cartography and two questionnaires administered to local inhabitants. It comprises eight phases - five of analysis and three of design - and a Phase 0 that consists in constructing the grid required for the operations which are to be implemented later. The product of the PlaceMaker method consists of two complex maps, one of analysis and of design, which represent place identity and project interventions in order both to establish a dialogue with local people and to complement traditional urban planning instruments as a means to make decisions taking account of the intangible aspects of an area.

The information collected by the surveyor and imported and systematized by the platform in the course of several surveys, questionnaires, and analysis is summarized in multimedia maps in the form of symbols. In Div@ter, places and elements identified with PlaceMaker method are represented by inserting symbols and elements into maps connected to multimedia schedules that can be 
continuously updated. In the first phase, devoted to anticipatory analysis, it is possible to directly insert the text in word format or make a sketch in electronic format (Fig. 3).

Once the analysis of the expectations has been carried out with a synthesis operation, it is necessary to assimilate a text, an image, or something else to a symbol; if the database does not contain the suitable symbol, an appropriate one can be created. Such data are necessary to construct the multimedia schedule to link to the symbols. In the second phase, once the five surveys have been carried out; in addition to the nominal database, the sketches in digital format, the images, and the videos are also inserted in PlaceMaker software. A second partial map with symbols and related multimedia schedule is constructed from the information obtained from the second phase (Figs 4-19).

With the third phase, the different types of maps which are used for the traditional analysis are imported by the software. The product of this phase is a map identifying the components required for the site description that can be found only through traditional planimetric interpretation. The symbols in this map will not be associated with a multimedia schedule but with those of two traditional maps.

In the fourth phase, the information obtained from the questionnaire is transferred onto the fourth partial map and the schedule for the symbols will mainly comprise images and written text.
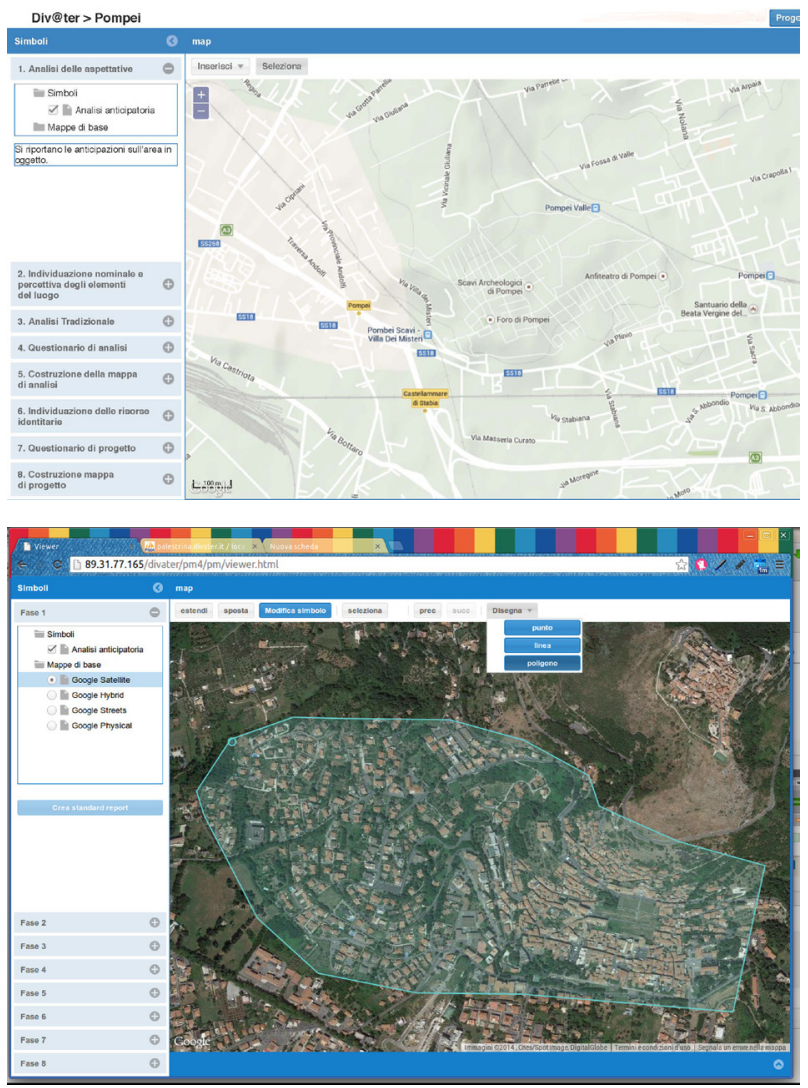

Figure 3: Div@ter platform. 

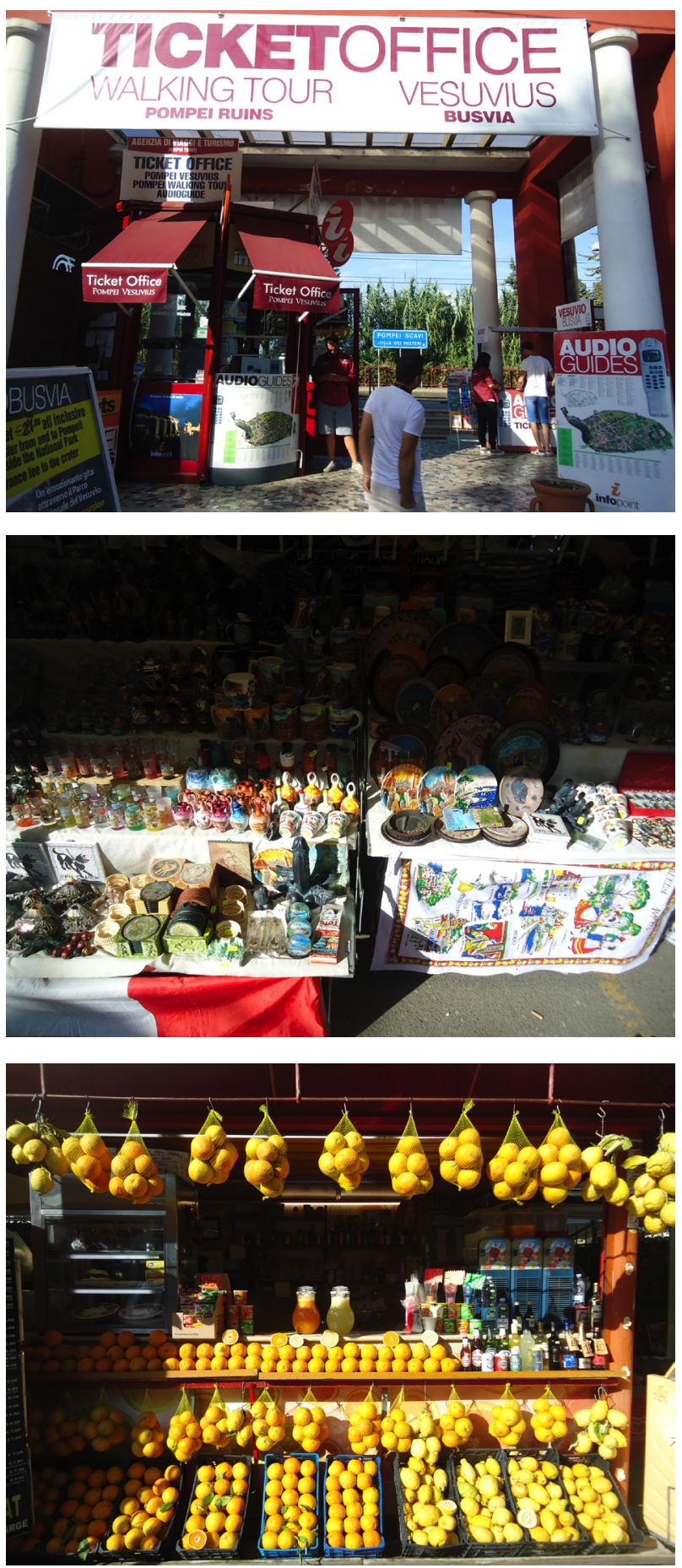


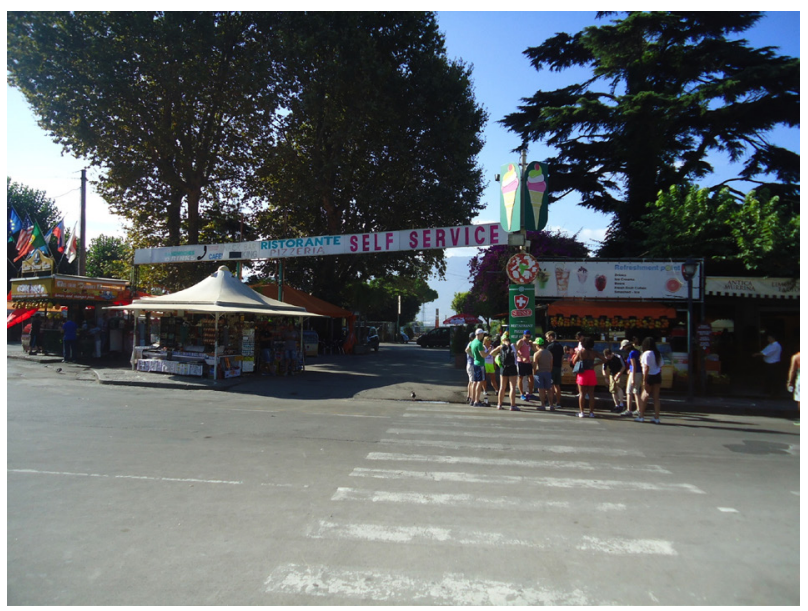

Figures 4-7: The first stretch of Via Plinio with street vendors.
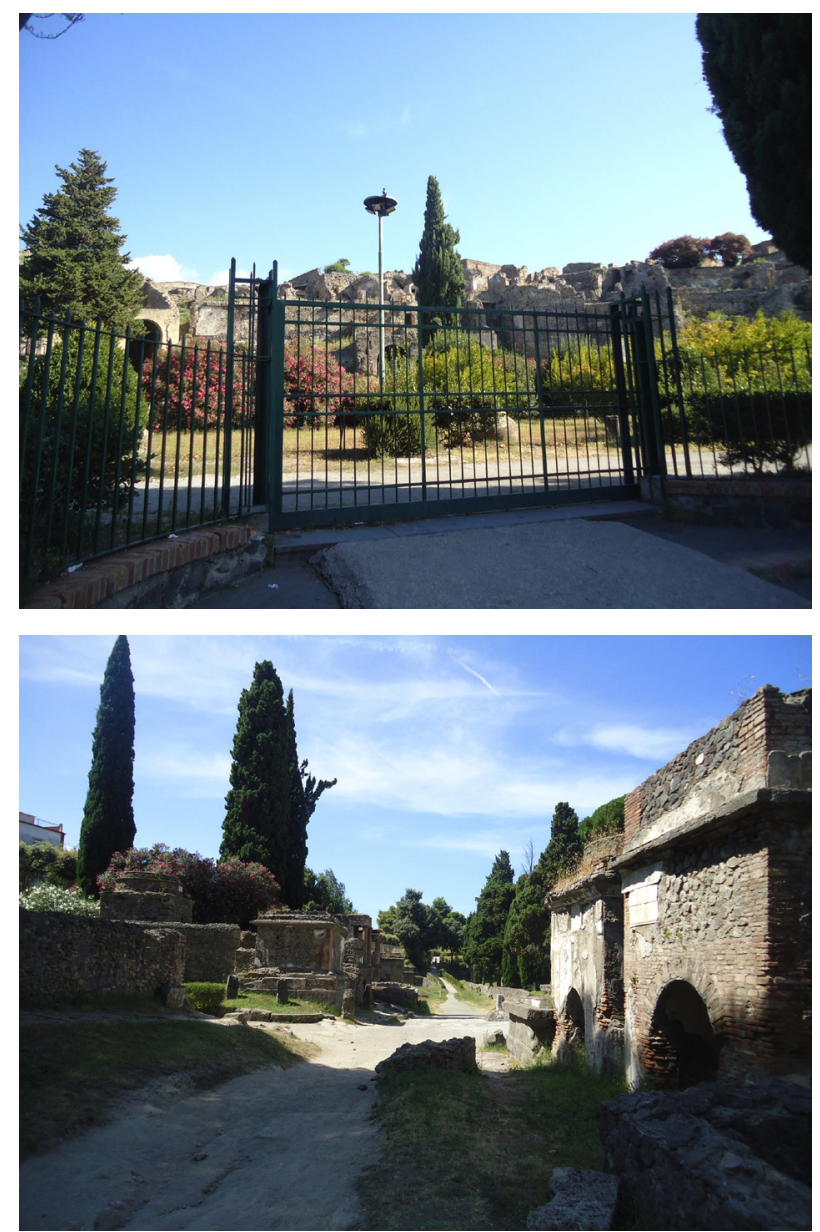

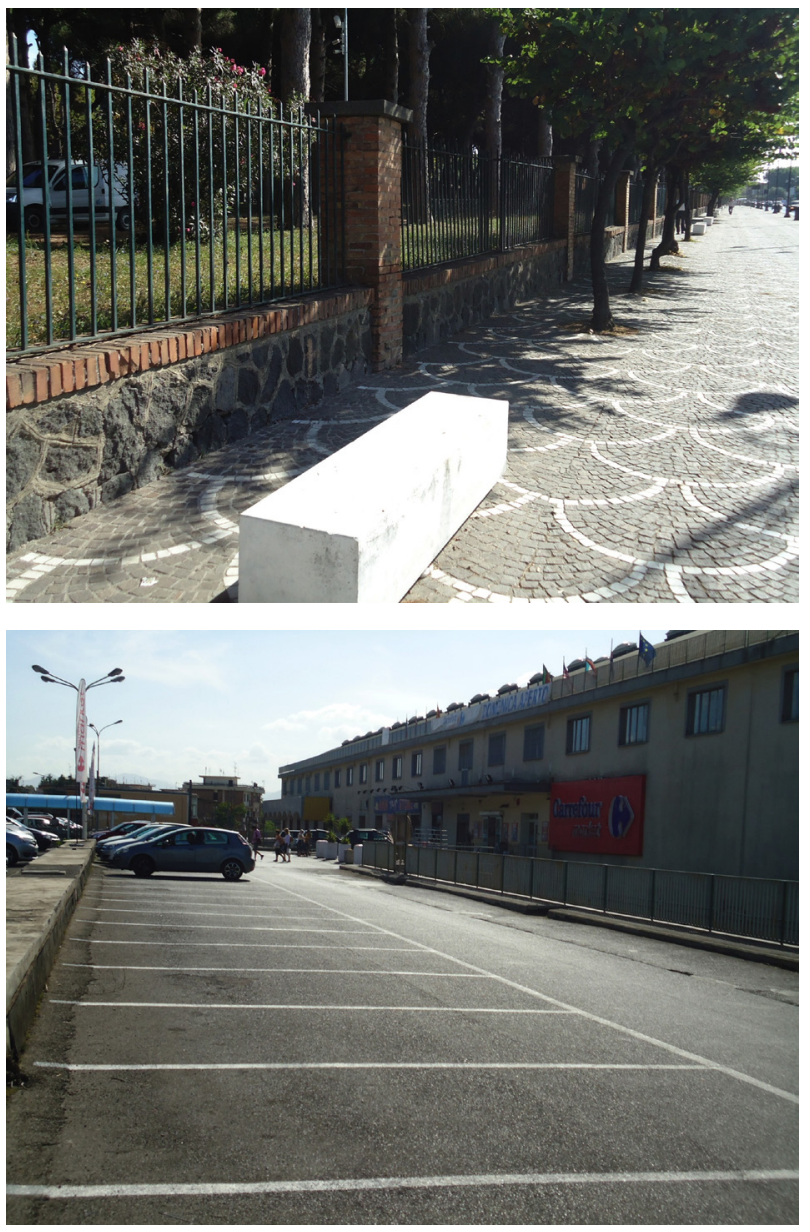

Figures 8-11: The second stretch of Via Plinio with the view of the ruins and the wide space close to the market.

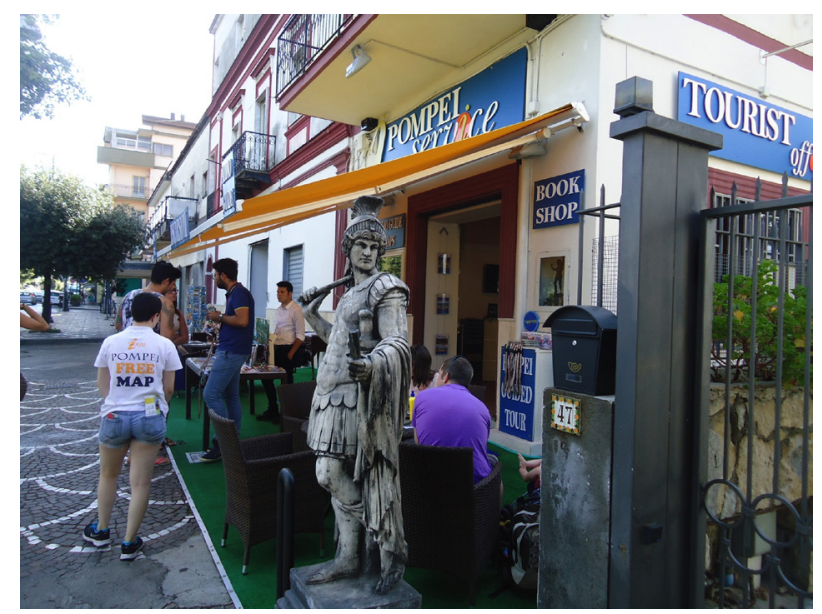



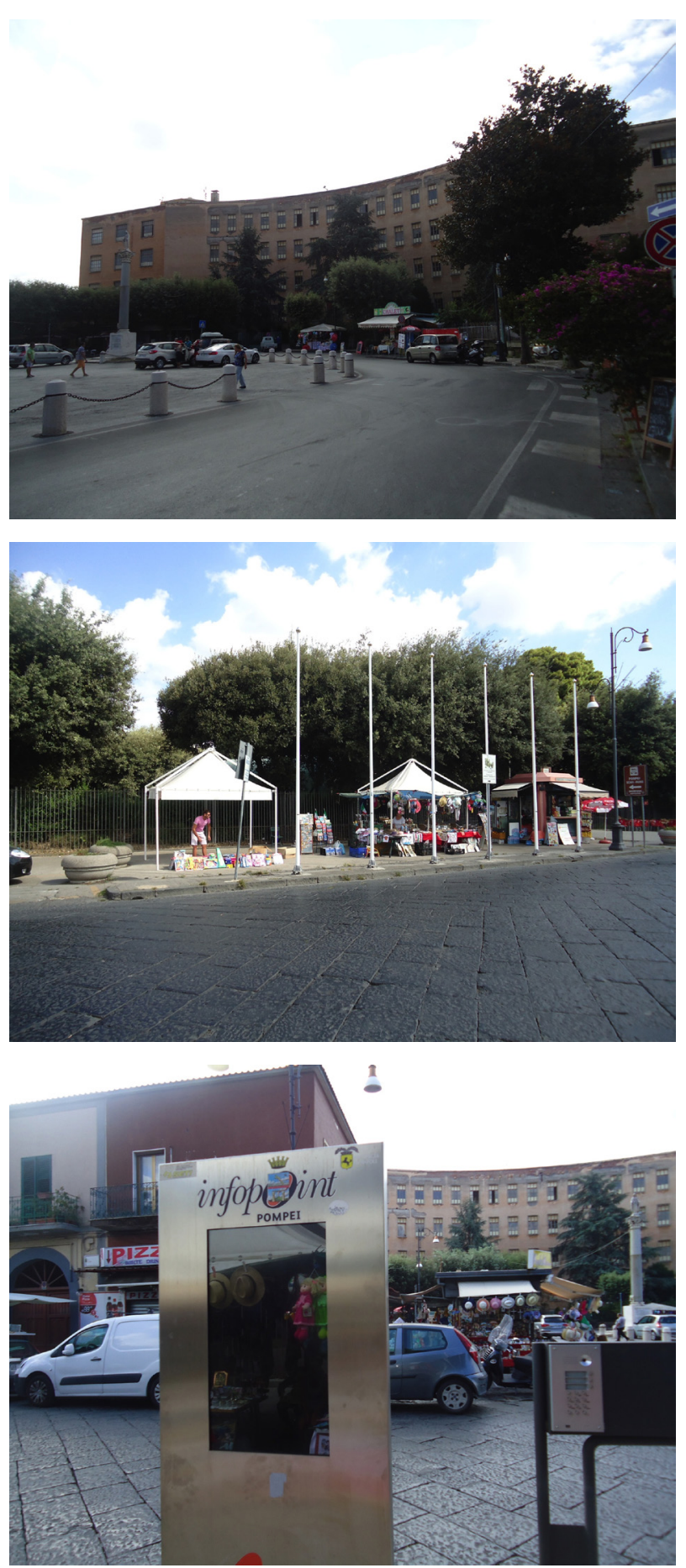

Figures 12-15: Via Plinio and Piazza Anfiteatro. 

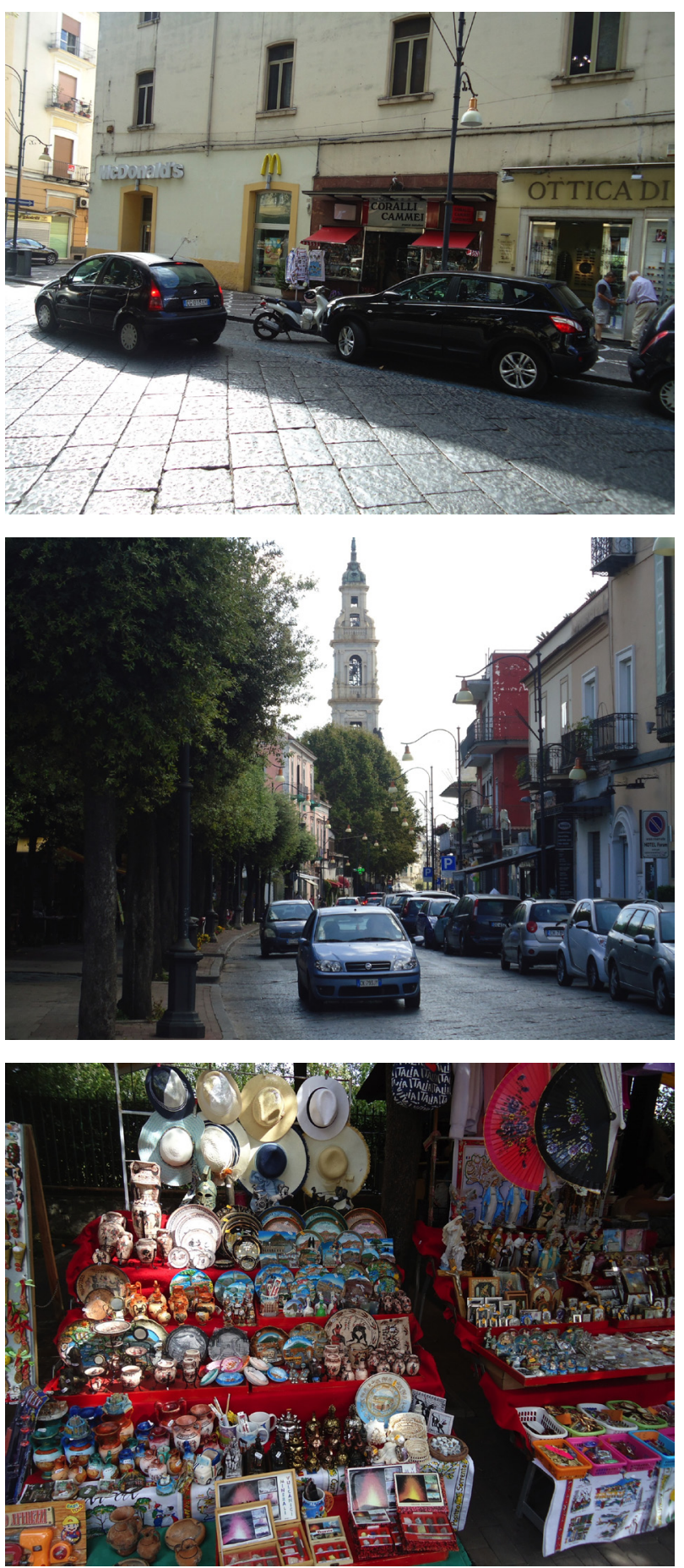


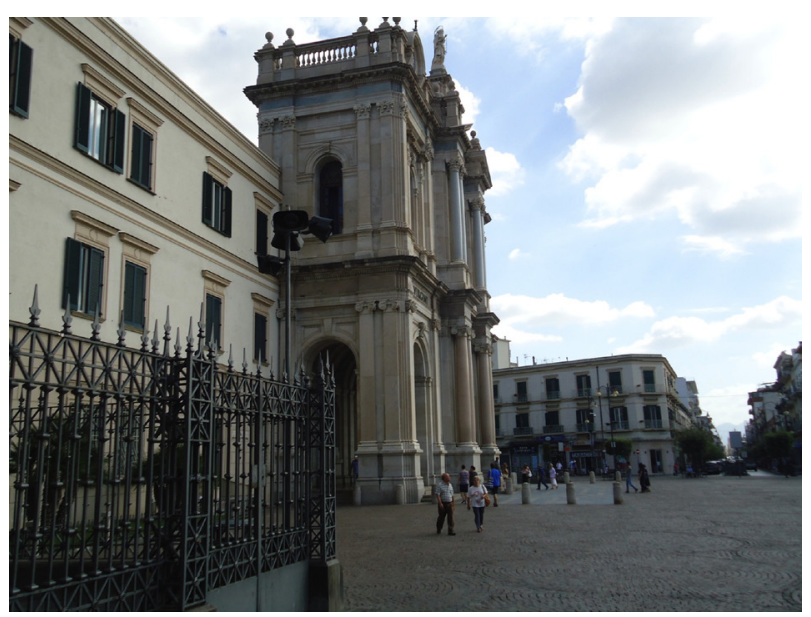

Figures 16-19: Via Roma, the last stretch of the path and the Pompeii Sanctuary.

In the fifth phase, involving assembly of the collected information, the recorded data represent the basis for the construction of the graphical system of symbols and the related multimedia schedule. By suitably overlaying the maps obtained from the previous phases, with the software it is possible to produce the final complex map with symbols and related schedule of synthese.

In the sixth phase, detecting the identity resources, the software allows the analysis map to be drawn up by selecting the elements which identify the potential, the critical issues, and quality with respect to the identity resources. This allows the construction of three maps to be superimposed and the identification of possible sites for project interventions. The connection to the multimedia schedule will be activated to one or more aggregated symbols related to such intervention areas.

In the project questionnaire phase, the seventh, the software functions are the same as for the questionnaire in the analysis phase. In this phase, the information will be imported by the software for constructing the map and the multimedia schedule, which lists the respondents' questions and answers. The software will also highlight the relationship between the answers given, nationality/ age of the respondent, and where the interview was administered.

In the last phase of the method, phase 8, the software allows us to process the results obtained in the analysis and design phases for the construction of the complex map of project. The schedules related to the symbols will address both data of project and analysis phases. For both the complex maps, the software will update the results by entering new data.

\subsubsection{The experiential path}

Our surveys, questionnaires, and area studies led me to concentrate my study on Via Plinio and Via Roma, the main thoroughfares connecting the Pompeii ruins, respectively, with the sea and the Sanctuary.

The resulting project is a virtual experiential path through Pompeii, inspired by the concept informing 'Restoring life in Pompeii: a sustainable development project for the Vesuvius area', a research project undertaken by the Study Centre of the Industrial Union Association.

The aim of this 'path' is to experience Pompeii from a different point of view, encouraging enjoyment of the place through its better and less well-known contemporary identity resources, including 
not only to its archaeological site but also, and particularly, its local cultural local roots [38]. Suitable methods and software tools for urban analysis and design study are called for to single out these resources.

Public spaces - the more interesting of which should be identified, and the most hidden popularized - should be reconnected to the archaeological site and the religious sanctuary. The network of public spaces with their different identities constitutes both a suitable cultural connection between the two kinds of attractions and an experiential path through the promotion of local products [39-43]. Public spaces are smartly connected to each other and to sensors and/or virtual tools installed in places where the history of local products is explained and information about them provided. The idea is to entice visitors to experience the less well-known local features of Pompeii. The possibility to interact with smartphones or tablets and live photos and comments during the visit enriches visitor experience [5, 44-48].

The paths involve different actions - which are the result of phase 8 of the aforementioned PlaceMaker protocol - as illustrated in the map.

The first action to be undertaken is Creating a Landscape Itinerary. The Pompeii landscape including the Vesuvius and Monti Lattari - is mainly experienced by the locals, who use Via Plinio and Via Roma to shop. Renovating these panoramic streets with benches, adequate paving and viewpoints onto the scenery would make them more attractive for visitors and tourists as well as locals. Furthermore, the installation of sensors to provide information about local products, the history, and the culture of this ancient place could offer visitors a new way to discover Pompeii.

The second action I propose is Creating a Perceptual Itinerary. All the parts of Pompeii could stimulate the senses in various ways. The Via Plinio-Via Roma stretch going towards the Sanctuary is already a silence area. The possibility to reach the Sanctuary along a route wholly devoted to meditation, with suitable stops and green spaces inviting visitors to perceive scenic views, the scents of nature, the taste of plants, the song of the birds, and the tactile perception of nature can make for a rich sensorial experience. Such an itinerary would make the most of the potential for meditation of the Piazza del Santuario and, in general, of the whole area, and invite visitors to experience these places of great sensorial attractiveness. Such an itinerary could also provide special perceptual experiences to visitors with physical disabilities.

The third action is Enhancing Public Spaces by creating or renovating public spaces for the socialization of locals and visitors. In Pompeii, what people mainly do is to visit the main attractions, viz., the archaeological ruins and the Sanctuary. The streets of Pompeii, and Via Plinio in particular, are not especially meant for socialization. This action specifically aims to create spaces where people can have the pleasure to stop and enjoy the place, or simply take a break after a tour.

Benches and other furniture designed to harmonize with the identity of the place, playgrounds for children, small gardens with local vegetation, light installations, and sensors are just some of the possible additions to these places.

The fourth action is Differentiating Activities. Creating new activities, besides the current handicraft and local product shops, to enhance available natural and cultural resources would favour the presence of visitors and, hence, of the locals at different times of the year.

A cultural container, which could dynamically exhibit the history of Pompeii and its eruptions, could induce people to do something else than shopping.

The fifth action is Organizing a Network of Archaeological areas. Herculaneum and Oplontis are archaeological areas very close to Pompeii. Suitable paths for ecological vehicles - including bikes, electric bus and cars, and boats - and pedestrian panoramic routes linking these three areas would improve visitor's access to these areas (Fig. 20). 


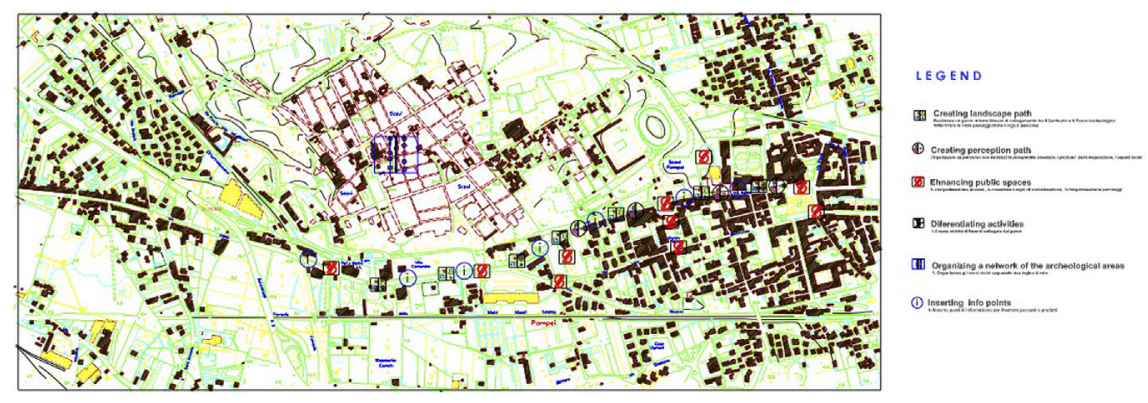

Figure 20: Pompeii. Complex map of design.

These paths should be equipped with sensors and information points which should inform about the history and culture of these places. An archaeological festival should be held periodically to draw people to experience the three areas.

Finally, the last action is the Creation of Information Points. To improve access to cultural and identity-related resources, information points and adequate signage are needed. The infopoints should be planned to provide information about the new itineraries, events, and typical products. They should be designed to harmonize with the ancient history and culture of the place. Each infopoint should be equipped with multimedia devices to visualize and navigate the multimedia maps of identity-related resources, and of itineraries and activities.

\section{CONCLUSION}

The present article has illustrated some of the main examples of experiential paths, concluding with the illustration of 'smart' paths using multimedia technologies that support the development of the local resources of an area in innovative way.

Today, new approaches to mapping the city have arisen, with the main purpose of identifying urban dynamicity by using direct observation supported by ad hoc electronic devices. The construction of experience is based on the creation of bottom-up and top-down networks. While in the first case a combination of businesses, stakeholders, and institutions allows the participation of different actors at all stages of the process, in the second case a network is created to serve the interests of economic actors. In both cases, the success of the operation depends on its sustainability understood in its threefold sense, taking care not to use up cultural resources and the environment, and to involve in decision-making both the local population and the companies that produce local products.

These factors are of specific interest for the object of the proposed study, viz., Pompeii. The use of technological tools serves the purpose of increasing the potential for innovation and regional competitiveness of Pompeii for both locals and visitors, and of avoiding simplification of information or marketing. I have illustrated the smart approach to placemaking and the new DIV@TER multimedia platform currently being developed. Div@ ter is a dynamic and interactive platform aimed at improving knowledge of the tangible and intangible resources of a place - which are often neglected by town smart services - to improve the quality of life of citizens and visitors and support local participation and planning. Div@ ter has used the PlaceMaker method protocol to identify elements that are not recognizable in traditional maps and which constitute the contemporary identity of places, and to outline the suitable actions for the protection and sustainable development of these places.

The project resulting using this protocol is a virtual experiential path of Pompeii, giving a specific outlet to the 'Restoring the life in Pompeii: a sustainable development project for the Vesuvius area' investigation carried out by the Study Centre of the Industrial Union Association. 
Pompeii, nowadays, receives huge inflows of tourists who are exclusively interested in the ruins or the Sanctuary. People usually stop there just for the time of the visit, and often come to Pompeii as part of a tour that Pompeii is only a part of. Due to the scarce attractiveness of the surroundings, only rarely do visitors decide to stay more than one day. On the other hand, locals, who usually visit the Sanctuary more often than the ruins, spend their time in the square in front of the Sanctuary or because of the lack of attractive places in the city - in the new shopping mall which has been opened not too far from Pompeii.

The new path is aimed at improving knowledge of Pompeii from a different point of view, encouraging enjoyment of this place starting from its best and less known contemporary identity resources, not only related to its archaeological site but also and in particular to its cultural and local roots.

It is meant to reconnect the public spaces lying between the archaeological site and the religious sanctuary. The network of public spaces with their different identities constitutes both a suitable cultural connection between the two kinds of attractions and an experiential path based on the promotion of local products.

The idea is to induce people to go on a smart and perceptive visit to experience the less wellknown features of Pompeii's landscape. These paths should be equipped with sensors and info points, which should inform about the history and culture of these places, immersing people in the atmosphere of the place in an innovative way.

The improvements I propose also take account of children's need for playgrounds and the elderly's need for recreational activities offering opportunities for socialization. They also strive to meet the residents' demand for agreeable places where to stop, and the demand of tourists, who are often pressed for time and could find in the sustainable attractions of the path a reason to slow down and relax. These paths should encourage more frequent use by locals and a sense of belonging to the ancient history of the place, participating more actively in its life, and combating in a sustainable manner the possible risk of globalization or gradual abandonment of the town, which would leave it only to the tourists.

\section{REFERENCES}

[1] Landry, C., The Creative City: A Toolkit for Urban Innovators. Earthscan: London, 2000.

[2] Florida R., The Rise of the Creative Class. And How It's Transforming Work, Leisure, Community and Everyday Life. Basic Books: New York, 2002.

[3] Duany, A., Speck, J. \& Lydon M., The Smart Growth Manual. McGraw-Hill: New York, 2010.

[4] Lupo, E. \& Özdil, E., Towards a "Smart Heritage" as future diffused museums: design and communication technologies to innovate the experience of the cultural patrimony in smart cities. The International Journal of the Inclusive Museum, 6 (1), 2011, pp. 159-169.

[5] Study Centre of the Industrial Union Association, Restoring life in Pompeii: A Sustainable Development Project for the Vesuvius Area, Rossi editori: Napoli, 2012.

[6] DETR/CABE, By Design: Urban Design and the Planning System: Towards Better Practice. DETR: London, 2000.

[7] Kolb, D.A., Experiential Learning: Experience As the Source of Learning and Development. Prentice-Hall: New Jersey, 1984.

[8] Capitello, R., Castellani, P. \& Rossato, C., Territorio, impresa e consumatore: percorsi esperienziali nelle imprese vitivinicole, XXIV Congresso Annuale di Sinergie, Università di Salento, Lecce, pp. 99-117, 2012.

[9] Falk P. \& Campbell, C., The Shopping Experience. Sage: London, 1997. 
[10] Menon S. \& Kahn B., Cross-category effects of induced arousal and pleasure on the internet shopping experience. Journal of Retailing, 78, 2002. doi: http://dx.doi.org/10.1016/s00224359(01)00064-1

[11] Rieunier, S. (ed.), Le marketing sensoriel du point de vente. Dunod: Paris, 2002.

[12] Splendiani, S., Pencarelli, T., Franch, M., De Salvo, P., Calzati, V. \& Splendiani, S., La valorizzazione del territorio in ottica esperienziale attraverso i percorsi del tipico: riflessioni teoriche ed evidenze empiriche in Italia, Proceedings of Aidea, 2013.

[13] Montella, M., Valore e valorizzazione del patrimonio culturale storico. Electa: Milano, 2009.

[14] Golinelli, C.M., Il territorio sistema vitale. Verso un modello di analisi, Giappichelli, Torino, pp. 13-14, 2002.

[15] Sepe, M., Creative urban regeneration between innovation, identity and sustainability. International Journal of Sustainable development, 12(2-4), pp. 144-159, 2009. doi: http:// dx.doi.org/10.1504/ijsd.2009.032775

[16] Sepe, M., Urban history and cultural resources in urban regeneration: a case of creative waterfront renewal. Planning Perspectives Journal, 28(4), 2013. doi: http://dx.doi.org/10.1080/026 65433.2013 .774539

[17] Landry, C., The creative city: its origins and futures. Urban Design Journal, 106, 2008.

[18] Carta, M., Creative City. LISt: Barcelona, 2007.

[19] Florida, R., Cities and the Creative Class. Routledge: London, New York, 2005.

[20] Ferilli, G. \& Pedrini, S., "Il distretto culturale evoluto alla base dello sviluppo sostenibile del territorio, Pre Proceedings of XII Convegno Internazionale Interdisciplinare Volontà, libertà e necessità nella creazione del mosaico paesistico-culturale, Cividale del Friuli-UD, 25-26 October, 2007.

[21] Nijkamp, P. \& Perrels, A.H., Sustainable Cities in Europe, Earthscan: London,1994.

[22] Nocifora, E., de Salvo, P. \& Calzati, V. (eds.), Territori lenti e turismo di qualità. Prospettive innovative per lo sviluppo di un turismo sostenibile. Franco Angeli: Milano, 2011.

[23] Lynch, K., The Image of the City. MIT Press: Cambridge, 1960.

[24] Degen, M.M. \& Rose, G.. The sensory experiencing of urban design: the role of walking and perceptual memory. Urban Studies, 49(15), pp. 3271-3287, 2012. doi: http://dx.doi. org/10.1177/0042098012440463

[25] Lefebvre, H., The Production of Space, Oxford: Blackwell, 1991.

[26] Klingman, A., Brandscapes: Architecture in the Experience Economy, MIT Press: Cambridge, 2007.

[27] Lehtovuori, P., Experience and Conflict: The Production of Urban Space, Ashgate: London, 2010.

[28] Seremetakis, N., The Senses Still: Perception and Memory as Material Culture in Modernity, Chicago University Press: Chicago, 1994.

[29] Eizenberg, E., Remembering forgotten landscapes: community gardens in New York City and the reconstruction of cultural diversity, T. and [29] Yacobi, H. (eds) Remembering, and Forgetting City Builders, eds. T. Fenster \& H. Farnham, Ashgate: London, 2010, pp. 7-26.

[30] Castells, M., The Informational City, Blackwell: Oxford, 1989.

[31] Sepe, M., Planning and Place in the City. Mapping Place Identity, Routlege: London, New York, 2013.

[32] Graham, S., Marvin, S., Splintering urbanism: networked infrastructures, technological mobilities and the urban condition. Routledge: London, New York, 2001.

[33] Anderson, B.R., Imagined Communities: Reflections on the Origin and Spread of Nationalism. Verso: London, 1991. 
[34] Frederick, H.H., Global Communication and International Relations, Wadsworth: Belmont, CA, 1993.

[35] Di Bari, V. \& Magrassi, P., 2015 Weekend nel Futuro, Edizioni Il Sole 24 Ore: Milano, 2005.

[36] Peano, A. \& Voghera, A., Smart landscape. Una nuova grammatica per la transizione urbana, Il mosaico paesistico-culturale in transizione: dinamiche, disincanti, dissolvenze, "Paysage Topscape” Oveview,, eds. T.F.M. Chang, L.C. Piccinini \& M. Taverna, vol. 9, 2011.

[37] Sepe, M., Preserving, reconstructing and enhancing the place identity: identifying principles of urban sustainability with placemaker method. International Journal of Sustainable Development and Planning, 9(2), pp. 277-300, 2014. doi: http://dx.doi.org/10.2495/sdp-v9-n2-277-300

[38] Sepe, M., Creating smart urban landscapes: a multimedia platform for placemaking, TEMA, Special Issue June 2014 on the Eighth International INPUT Conference Smart City Planning for Energy, Transportation and Sustainability of the Urban System, pp. 897-907, 2014.

[39] Buttimer, A. \& Seamon, D., The Human Experience of Space and Place, St Martin's Press: New York, 1980.

[40] Carmona, M., Design coding and the creative, market and regulatory tyrannies of practice. Urban Studies, 46, pp. 2643-2667, 2009. doi: http://dx.doi.org/10.1177/0042098009344226

[41] Castello, L., Rethinking the Meaning of Place: Conceiving Place in Architecture - Urbanism. Ashgate: London, 2010.

[42] Cronin, A. \& Hetherington, K., Consuming the Entrepreneurial City: Image, Memory, Spectacle. Routledge: London, 2008.

[43] Feld, S., Places sensed, senses placed, Empire of the Senses, ed. D. Howes, Oxford: Berg, 2005.

[44] Grant, J., Experiential planning. Journal of the American Planning Association, 75, pp. 358-370, 2009. doi: http://dx.doi.org/10.1080/01944360902965875

[45] Zardini, M., Toward a sensorial urbanism, Sense of the City, ed. M. Zardini, Lars Muller Publishers: Montreal, pp. 17-33, 2008.

[46] Sepe, M. \& Pitt, M., The characters of place in urban design, Urban Design International, Advance online publication 8 January 2014; doi: 10.1057/udi.2013.32, 2014.

[47] Urry, J., Consuming Places, Routledge: London, 1995.

[48] Sepe, M., Smart experiential paths and Historical Urban Landscape: a case of sustainable enhancement, WIT Transactions on Ecology and The Environment, 191, pp. 1153-1164, 2014, ISSN 1743-3541. doi: http://dx.doi.org/10.2495/sc140972 